www.jwd.unram.ac.id

Vol. 1 NO. 3 Desember 2019

\title{
GERAKAN ZERO WASTE SEBAGAI PENDIDIKAN LINGKUNGAN BERSIH
}

\author{
I Gusti Ngurah Yudi Handayana1*, Lily Maysari Angraini ${ }^{1}$, I Wayan Sudiarta ${ }^{1}$, Nurul Qomariyah", \\ Siti Alaa'1 \\ ${ }^{1}$ Program Studi Fisika, Fakultas MIPA, Universitas Mataram (arial 10) \\ ${ }^{*}$ Co-Author :ngurahyudi@unram.ac.id
}

\begin{abstract}
ABSTRAK. Zero waste merupakan pandangan baru dalam manajemen sampah, yang mengedepankan prinsip 3R (Reuse, Reduce, dan Recycle). Prinsip ini dianggap mampu dalam menanggulangi dampak sampah pada lingkungan. Tujuan dari kegiatan ini adalah menggalakkan gerakan lingkungan bersih berdasarkan prinsip 3R. Gerakan ini diterapkan kepada siswa SMPN 2 Sekotong, Lombok Barat sebagai mitra kegiatan. Berdasarkan analisis permasalahan dengan 4 tinjauan (Surrounding, Skills, Systems, dan Supplier), permasalahan mitra adalah siswa belum memahami penanganan sampah secara mandiri di lingkungan sekolah karena belum memiliki literatur tentang penangan sampah zero waste, belum optimalnya fasilitas yang dapat digunakan dalam pengelolaan sampah secara zero waste, teknis pengelolaan sampah yang belum berjalan, serta keterampilan dalam pengelolaan sampah secara mandiri belum terlatih. Solusi yang ditawarkan menyelesaiakan permasalahan mitra terdiri dari 2 tahap, yaitu tahap direct instruction dan tahap aksi nyata gerakan bersih lingkungan. Hasil kegiatan ini adalah terbentuknya pemahaman siswa-siwa mitra dalam melaksanakan gerakan zero waste, mulai dari proses pemilahan, pengumpulan, dan pemanfaatan sampah sebagai barang yang berguna dan bernilai tambah. Hasil lainnya adalah terciptanya lingkungan yang bersih mulai dari diri mitra untuk mengurangi sampah dan memanfaatkan sampah menjadi barang ekonomis seperti pengolahan sampah plastik menjadi paving blok.
\end{abstract}

Kata Kunci: zero waste, lingkungan, reduce, reuse, recycle

ABSTRACT. Zero waste is a new perspective in waste management, which promotes the principle of 3R (Reuse, Reduce, and Recycle). This principle is considered capable of overcoming the impact of waste on the environment. The purpose of this program is to promote a clean environmental habits based on the $3 R$ principle. This program is applied to students of SMPN 2 Sekotong, West Lombok, as a partner. Based on the problem analysis, students do not understand how to handle waste independently in the school environment because they do not have literature on zero waste management, there are not optimal facilities yet that can be used in waste management zero waste, no waste management techniques, and skills in waste management have not been trained. The solution for the partner's problem consisting of 2 steps, there are the direct instruction and the real action of the clean environment. The result of this program is student's understanding in implementing the zero waste management, starting from the process of sorting, collecting, and utilizing waste as useful and value-added things. Another result is clean environment starting from the students themselves to reduce waste and make use of waste into economic things such as processing plastic waste into paving blocks.

Keyword: zero waste, lingkungan, reduce, reuse, recycle 


\section{PENDAHULUAN}

Zero waste merupakan filsafat yang mendorong perancangan ulang suatu sumber daya dari sistem linier menuju siklus tertutup, sehingga semua produk dapat digunakan kembali. Bebas sampah (zero waste) mengacu pada pengelolaan sampah dan pendekatan perencanaan yang menekankan pencegahan produksi sampah. Hal ini berlawanan dengan pendekatan pengelolaan sampah selama ini, yang menekankan pengolahan sampah yang sudah dihasilkan (Snow W, Dickinson J, 2001). Zero waste merupakan pemahaman yang lebih dari sekedar mendaur ulang sampah, mencakup pencegahan dan pengurangan sampah (Davidson $\mathrm{G}, 2011$ ). Prinsip zero waste secara umum adalah 3R yaitu Reduce, Reuse, dan Recycle, serta prinsip pengolahan sampah sedekat mungkin dengan sumber sampah untuk mengurangi beban pengangkutan.

Zero waste menjadi suatu pandangan baru dalam manajemen sampah, mengingat isu sampah telah mencapai level yang menghawatirkan. Isu sampah, terutama sampah plastik, menjadi perhatian serius karena produksi plastik berdasarkan data ourworldindata.org mengalami peningkatan drastis yang mencapai 381 juta ton di tahun 2015 (Ritchie H, Roser M, 2018). Bahkan kompas.com telah menuliskan bahwa Indonesia termasuk dalam Negara yang mengalami darurat sampah (Kompas, 2016, 2018). Kondisi ini mengancam ekosistem dan lingkungan, sehingga perlu penanganan khusus. Penanganan ini dapat dimulai dari regulasi dari masing-masing stakeholder di dunia.

Pemerintah Indonesia telah mencanangkan program Indonesia Bebas Sampah 2020. Melalui Kementerian Lingkungan Hidup, pemerintah mengharapkan perubahan cara pandang masyarakat terkait sampah melalui kemandirian pengelolaan sampah. Gerakan ini diterapkan di seluruh wilayah Indonesia, termasuk di provinsi Nusa Tenggara Barat. Gerakan ini pernah dilaksanakan oleh Zambana, FL, et al. (2019) namun terbatas di Desa Jerowaru, Lombok.

Provinsi Nusa Tenggara Barat memiliki kebijakan pengelolaan sampah melalui peraturan daerah. Hampir di setiap kabupaten/kota telah menerbitkan peraturan daerah tentang pengelolaan sampa, seperti Peraturan Daerah Kota Mataram Nomor 10 tahun 2018 tentang Pengelolaan Sampah serta Peraturan Daerah Kabupaten Lombok Barat Nomor 3 Tahun 2017 tentang Pengelolaan sampah. Berdasarkan Peraturan Daerah ini, sampah bukan lagi hanya menjadi tanggung jawab pemerintah, namun membutuhkan partisipasi setiap orang. Dalam hal ini, budaya pengelolaan sampah harus diedukasi sejak dini dan di setiap lapisan masyarakat.

Oleh karena itu, perlu gerakan dari berbagai elemen termasuk perguruan tinggi serta lembaga pendidikan dalam upaya penanggulangan sampah. Berdasarkan hal ini tim pengabdian program studi fisika berupaya berperan untuk memberikan edukasi dan menumbuhkan budaya pengelolaan sampah melalui gerakan zero waste. Tempat pengabdian dipilih di SMP N 2 Sekotong, Kabupaten Lombok Barat.

\section{ANALISIS PERMASALAHAN}

SMPN 2 Sekotong merupakan SMP yang terletak di Kecamatan Sekotong, Kabupaten Lombok Barat, Provinsi Nusa Tenggara Barat. Sekolah ini merupakan sekolah menengah Negeri yang telah terakreditasi A. Terletak di tanah seluas $18.000 \mathrm{~m}^{2}$, SMP N 2 Sekotong memiliki jumlah siswa sebanyak 523 orang dengan rincian siswa kelas 7 sebanyak 185 orang, siswa kelas 8 sebanyak 156 orang, dan siswa kelas 9 sebanyak 182 orang (dapo.dikdasmen.kemendikbud, 2019). 
Berdasarkan profil dari SMP N 2 Sekotong, maka permasalahan yang didapat adalah sampah masih dikelola secara linier. Sampah hanya dibuang di tempat sampah tanpa memperhatikan kriteria, jenis, dan sifat sampah. Hal ini dapat dikarenakan oleh hal-hal sebagai berikut.

1. Siswa belum memahami penanganan sampah secara mandiri di lingkungan sekolah karena belum memiliki literatur tentang penangan sampah zero waste (Surrounding).

2. Belum optimalnya fasilitas yang dapat digunakan dalam pengelolaan sampah secara zero waste (Supplier).

3. Teknis pengelolaan sampah yang belum berjalan (System)

4. Keterampilan dalam pengelolaan sampah secara mandiri belum terlatih (Skill)

Semua masalah tersebut bermuara pada belum adanya budaya gerakan zero waste dalam penanganan sampah, yang bersumber pada 4S (surrounding, supplier, system, dan skill). Masalah yang dihadapi mitra tersebut dapat dibuatkan dalam bentuk fishbone diagram seperti gambar 1 .

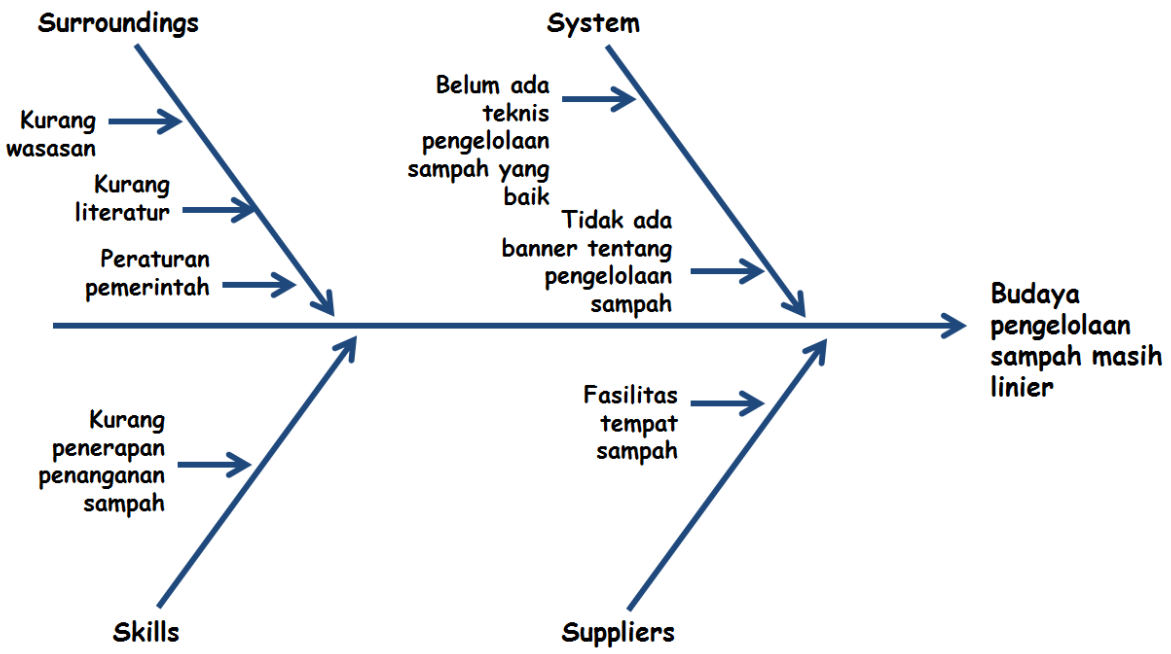

Gambar 1. Fishbone diagram permasalah mitra dengan analisis 4S (Surroundings, Skills, System, danSuppliers)

\section{SOLUSI YANG DITAWARKAN}

Berdasarkan rincian permasalahan yang dihadapi mitra, maka beberapa solusi yang ditawarkan (1) Memberikan edukasi tentang penanganan sampah sejak dini melalui gerakan zero waste, (2) Optimalisasi fasilitas yang ada sebagai bank sampah yang sesuai dengan sifat dan jenis sampah (3) Merealisasikan gerakan zero waste melalui kegiatan pembersihan, pemisahan, dan penanggulangan sampah sesuai prinsip $3 \mathrm{R}$ (reduce, reuse, dan recycle). Pada pelaksanaan kegiatan ini, metode yang akan digunakan adalah (1) Direct Instruction dan Focus Group Discuss, dan (2) Gerakan nyata pembersihan lingkungan pengelolaan sampah menerapkan zero waste.

\section{Tahap 1}

Metode pertama Direct Instruction digunakan untuk memberikan penjelasan tentang : a) pengenalan zero waste management, b) pengurangan, pemilahan, dan pemanfaatan sampah.

\section{Tahap 2}


Metode kedua adalah gerakan nyata melalui pembersihan di lingkungan sekolah serta penerapan manajemen sampah yang telah diberikan.

\section{HASIL DAN PEMBAHASAN}

Gerakan Zero waste sebagai Pendidikan Lingkungan Bersih dilaksanakan di SMPN 2 Sekotong, Lombok Barat. Peserta diambil dari siswa kelas IX. Antusiasme peserta sangat terlihat dari mulai dilaksanakan persiapan di ruang kelas (untuk kegiatan direct instruction).

Pemberian materi dimulai dari penjelasan mengenai lingkungan dan kondisi Planet Bumi. Mengingat peserta adalah siswa SMP, maka perlu dilakukan brainstorming melalui pemberian materi yang ringan dan menarik tentang alam. Siswa sangat antusias mengikuti pemaparan materi, diselingi beberapa pertanyaan dari siswa terkait materi yang disampaikan.

Inti materi yang disampaikan adalah mengenai kondisi lingkungan terkini yang sangat memprihatinkan terkait sampah plastik. Selain itu, dipaparkan jenis-jenis sampah dan jangka waktu terurai secara alami. Cara menghindari, mengolah, dan menyingkirkan sampah (Moerdjoko S, Widyatmoko, 2012) dan kondisi dan berita-berita terkini terkait kasus-kasus lingkungan yang terkait dengan sampah juga disampaikan kepada siswa. Hal ini dilakukan agar siswa sadar bahwa kondisi lingkungan sudah sedemikan menghawatirkan, sehingga perlu peran setiap orang dalam menjaga lingkungan. Materi inti yang disampaikan adalah mengenai prinsip zero waste sebagai salah satu alternatif dalam menjaga lingkungan dari efek negatif sampah. Prinsip 3R (reuse, reduce dan recycle) sebagai inti dari gerakan zero waste dipaparkan secara rinci. 


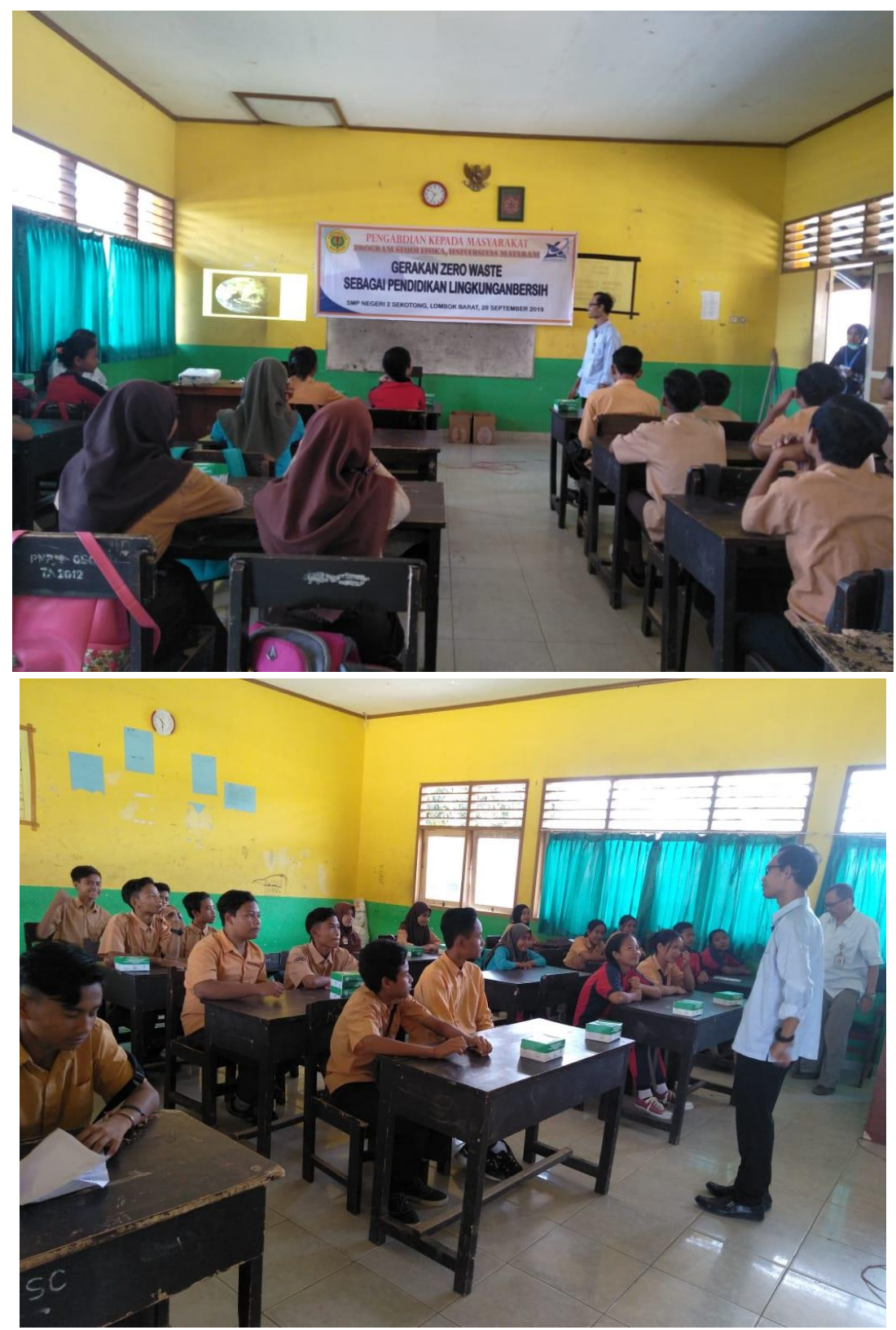

Gambar 2 Siswa menyimak penyampaian materi (tahap 1, direct instruction) dari tim pengabdian

Pada gambar 2, terlihat siswa menyimak materi yang disampaikan oleh tim pelaksana pengabdian. Mengingat materi zero waste baru pertama diketahui oleh siswa, maka siswa memiliki banyak pertanyaan mengenai prinsip Reuse, Reduce, dan Recycle. Beberapa contoh kegiatan yang terkait 3R disampaikan dengan baik kepada siswa. Tim pelaksana sesekali memberikan pertanyaan dan mengajak siswa untuk mengulang jargon prinsip 3R sebagai bagian dari penghayatan.

Hal menarik yang didapat dari kegiatan direct instruction bahwa di sudut kelas terdapat karung-karung yang digunakan untuk menyimpan sampah-sampah plastik. Ternyata, sampah plastik dikumpulkan untuk dijadikan paving blok dalam mata pelajaran keterampilan. Siswa hanya melakukan instruksi mengumpulkan sampah-sampah tanpa tahu bahwa apa yang dilakukan merupakan bagian dari gerakan zero waste. Karena kurangnya pemahaman dan hanya mengikuti 
instruksi, maka siswa kurang bersemangat dalam melakukan pengumpulan sampah. Setelah menerima penjelasan dari tim pengabdian mengenai gerakan zero waste, siswa menjadi paham dan antusias dalam mengumpulkan sampah plastik dan tentu saja berkomitmen untuk memulai menerapkan prinsip 3R.

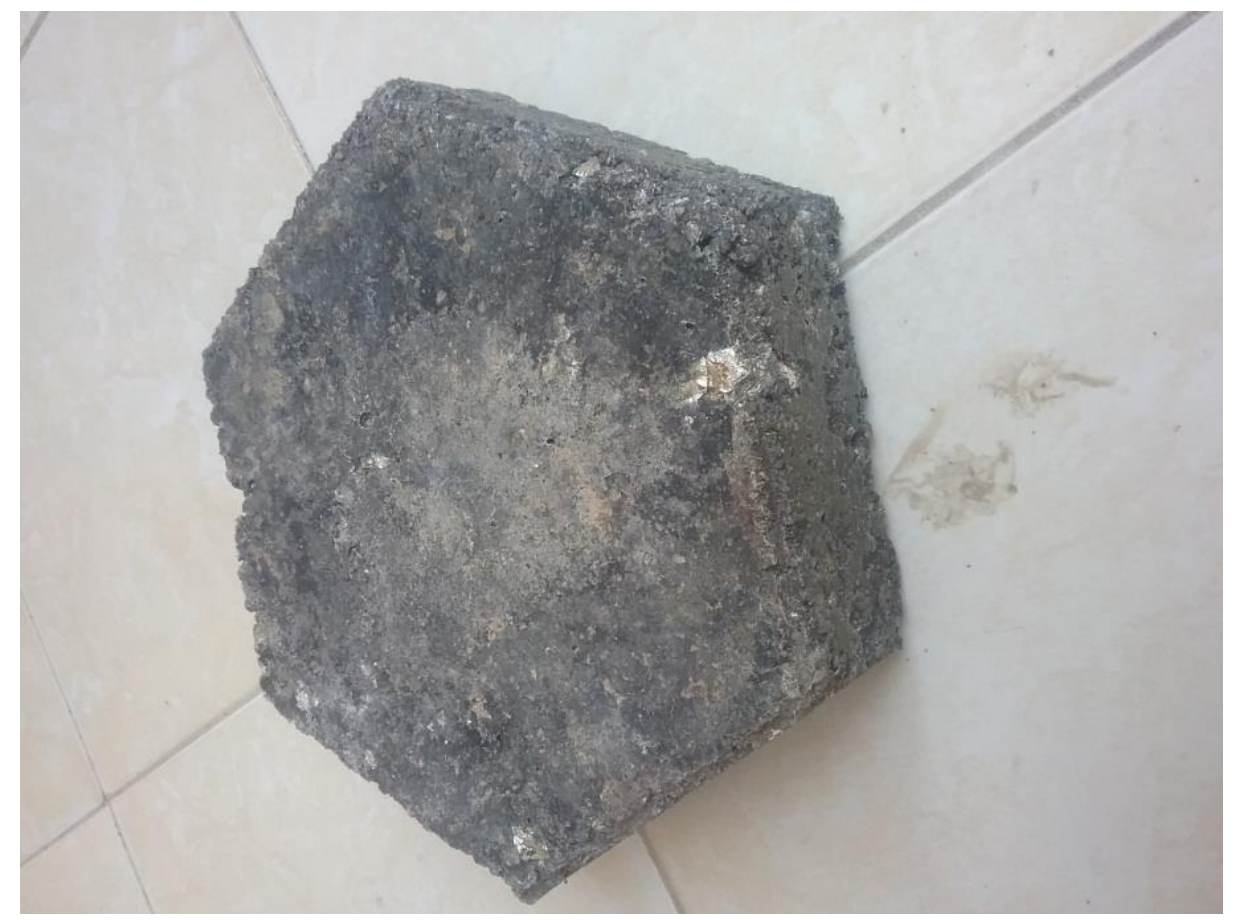

Gambar $3 \quad$ Paving blok yang dibuat oleh siswa sebagai pemanfaatan sampah plastik

Pada kegiatan direct instruction, masing-masing siswa diberikan kudapan snack. Kemudian, sebagai persiapan pelaksanaan kegiatan aksi nyata dari gerakan zero waste, siswa diminta untuk memilah sampah dari kudapan yang diberikan. Sampah-sampah yang telah dipilah dari kotak kue masing-masing kemudian dikumpulkan dalam tempat yang berbeda-beda, seperti terlihat pada gambar 4.

Pada gambar 4, siswa antusias mengumpulkan sampah dari kotak kue masing-masing. Sebagian siswa telah benar meletakkan sampah pilahannya sesuai tempat yang disediakan. Walau begitu, masih terdapat beberapa sampah yang salah tempat, seperti sampah plastik yang berada di sampah kertas. Hal ini kemudian ditekankan sekali lagi oleh tim pengabdian, bahwa sekecil apapun sampah tersebut, wajib dipilah dan dikumpulkan dengan sampah sejenis. Hal ini dilakukan untuk memberikan penekanan kepada siswa agar tidak pernah menyepelekan hal sekecil apapun. 


\section{Jurnal Warta Desa}

www.jwd.unram.ac.id

Vol. 1 NO. 3 Desember 2019
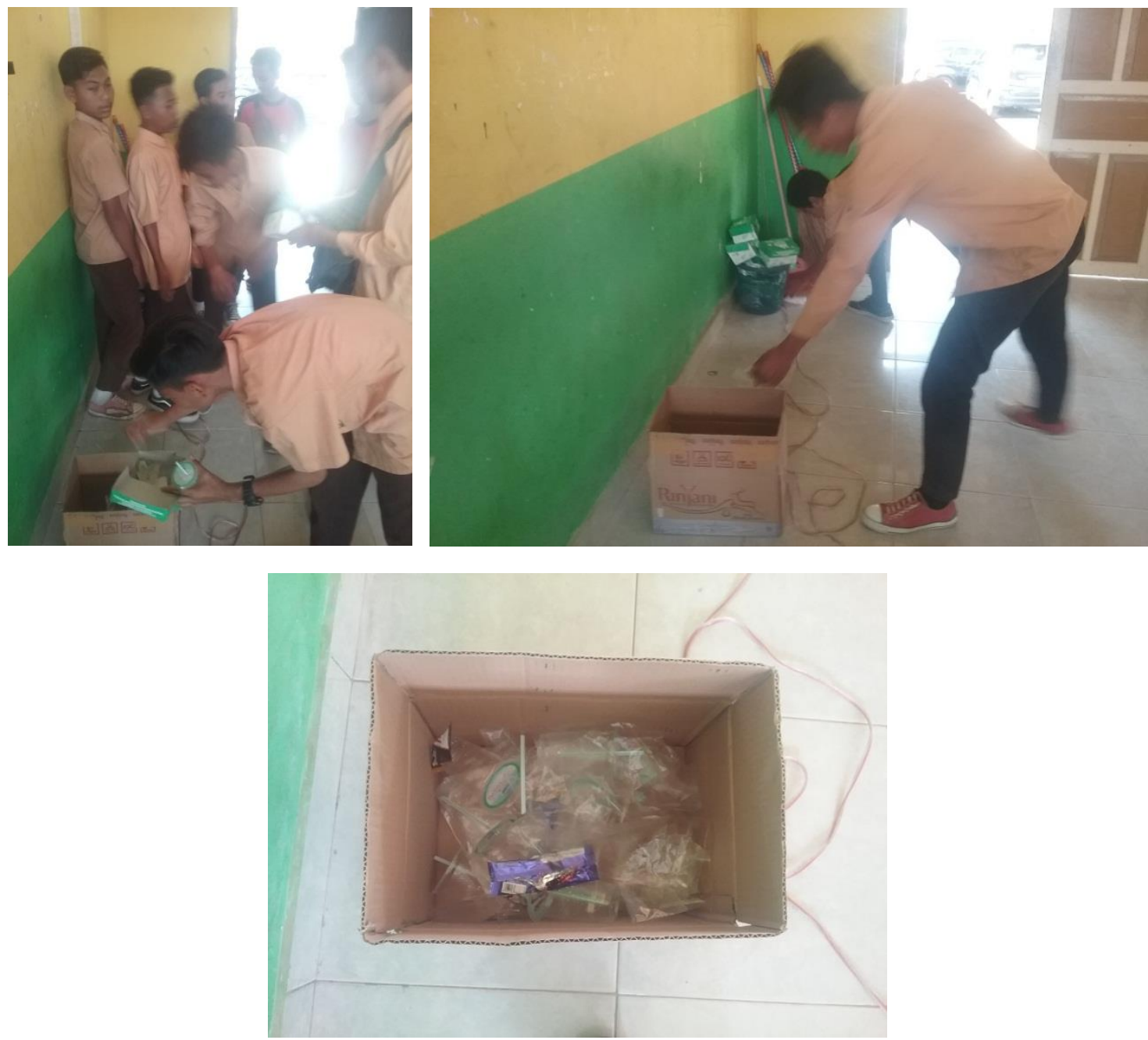

Gambar 4 Simulasi pemilahan dan pengumpulan sampah kotak kue masing-masing siswa serta hasil sampah yang berhasil dipilah dan dikumpulkan

Kegiatan selanjutnya adalah aksi nyata gerakan zero waste dengan melakukan pembersihan dan pemilahan sampah di lingkungan sekolah. Semua peserta diajak berkeliling sekolah untuk memungut sampah dan memilah sampah plastik dengan sampah lainnya. Selain itu, sampah yang sudah terkumpul di tempat sampah pun dibongkar lagi untuk memilah sampah-sampah sesuai jenisnya. Sampah plastik secara khusus dikumpulkan dalam karung-karung yang telah dibagikan. 

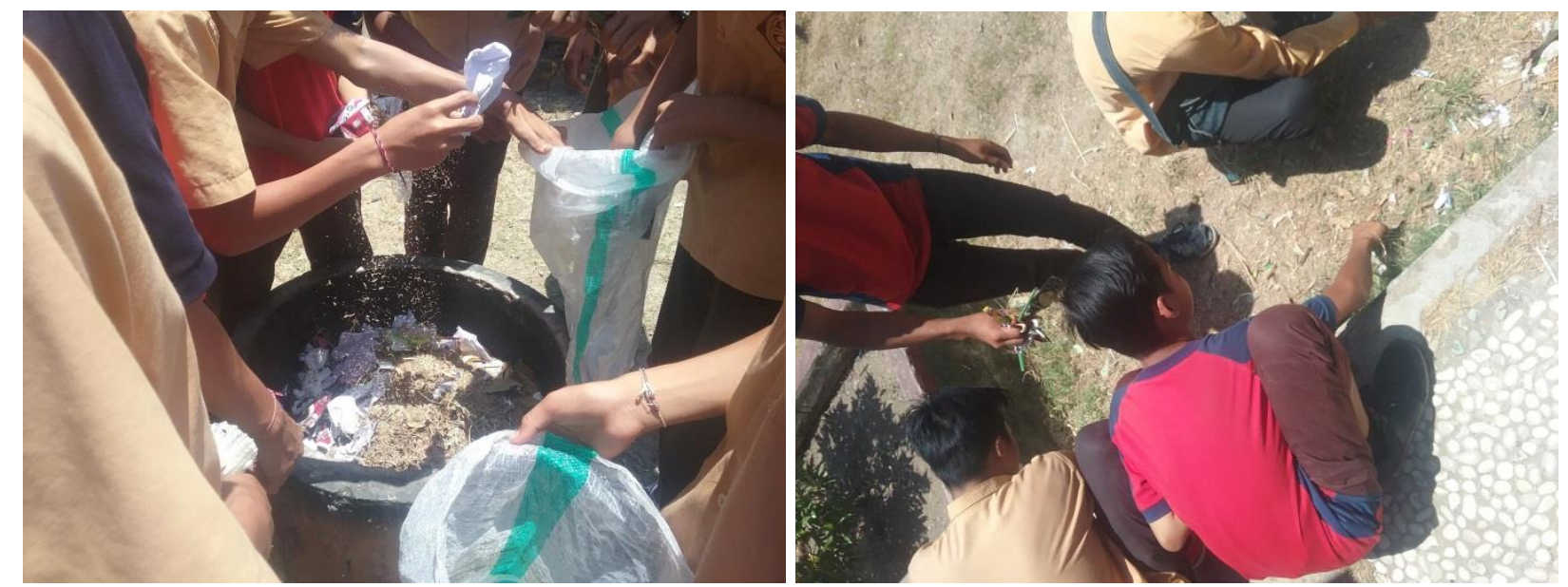

Gambar 5 Aksi nyata pembersihan, pemilahan, dan pengumpulan sampah di lingkungan sekolah

Pada gambar 5, terlihat siswa antusias dalam melaksanakan aksi nyata gerakan zero waste. Tanpa peduli terik matahari serta kotoran dari sampah dan tempat sampah, siswa bahu-membahu dalam mengumpulkan dan memilah sampah-sampah dari tempat sampah. Hasilnya, berhasil dikumpulkan sampah-sampah plastik yang terkumpul dalam karung-karung seperti terlihat pada gambar 6. Sampah plastik tersebut nantinya akan digunakan sebagai bahan baku pembuatan paving blok.

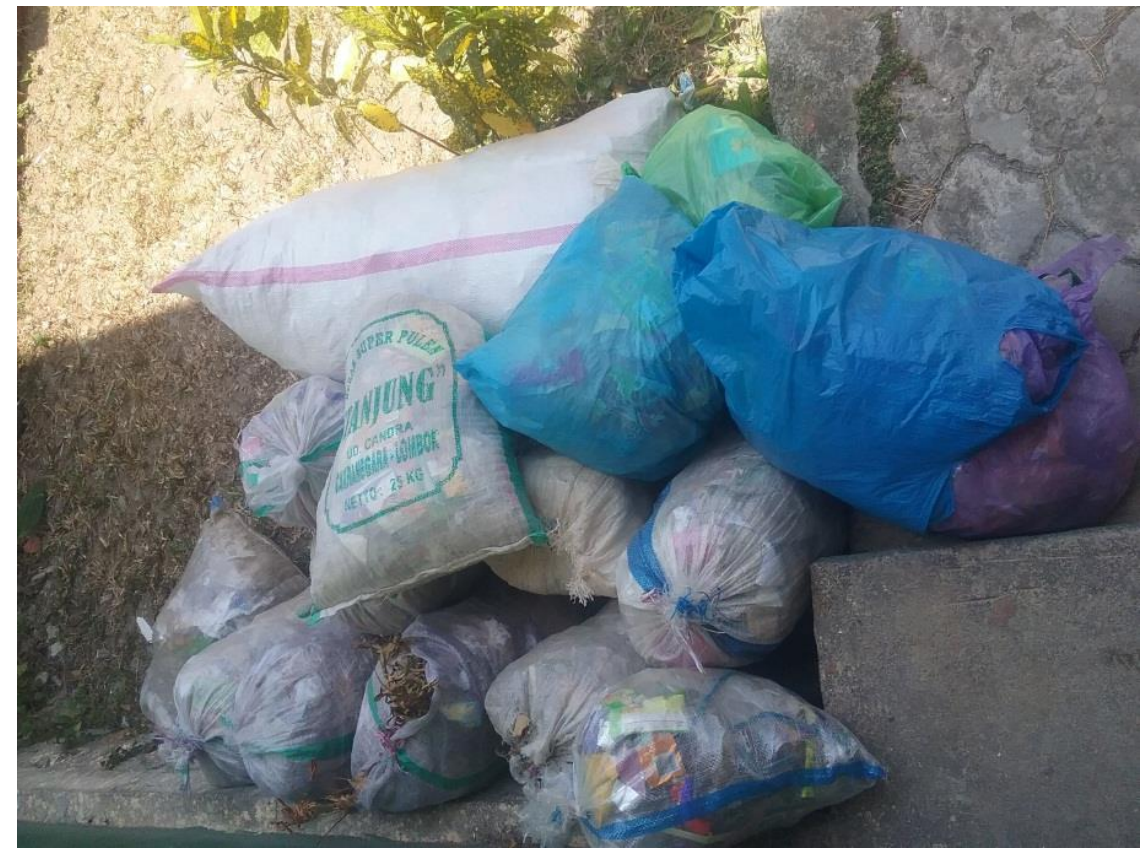

Gambar 6 Sampah plastik yang berhasil dipilah dan dikumpulkan sebagai bahan baku pembuatan paving blok 


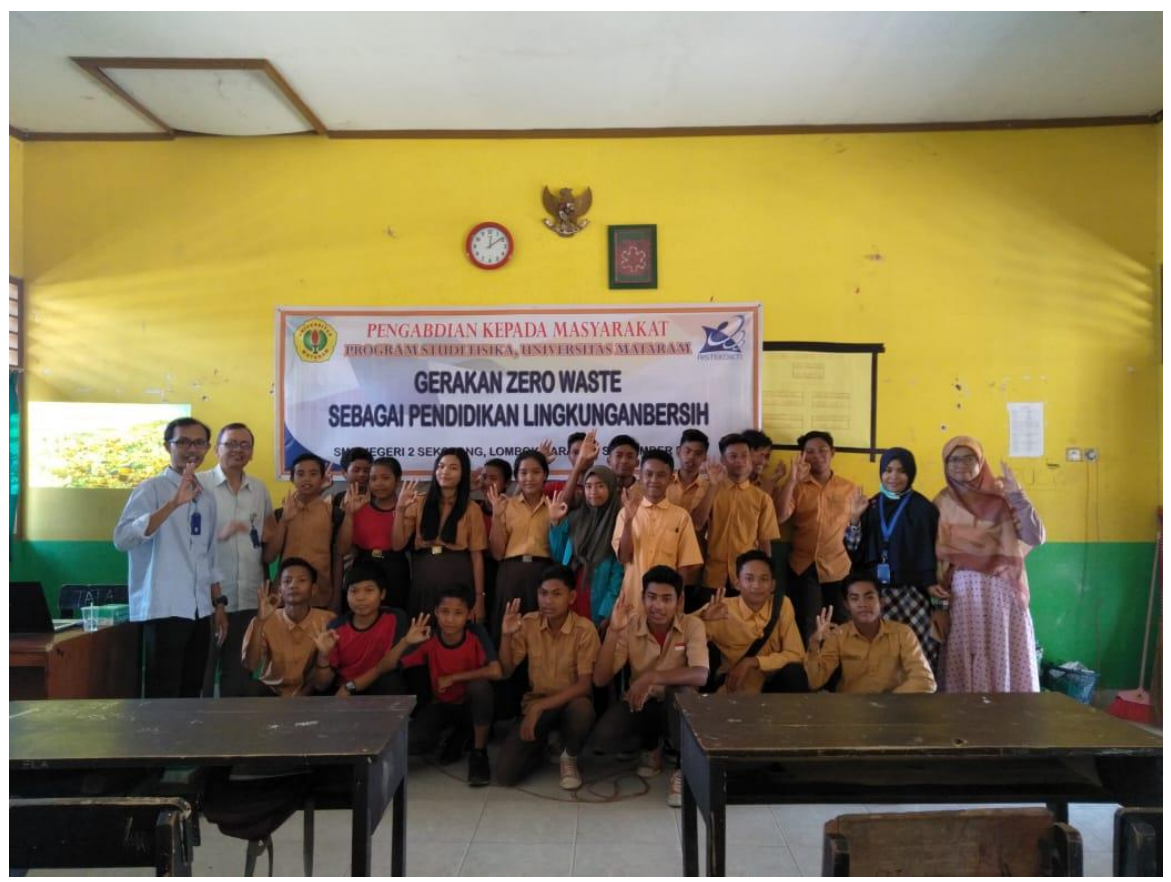

Gambar $7 \quad$ Peserta dan Tim Pengabdian berfoto bersama pada akhir kegiatan

Kegiatan terakhir adalah kembali ke ruangan untuk memberikan penekanan dan evaluasi kegiatan aksi nyata. Siswa diingatkan untuk selalu mengingat dan melaksanakan prinsip 3R, serta tidak lagi mengumpulkan sampah dalam 1 tempat sampah tanpa dipilah terlebih dahulu. Kegiatan diakhiri dengan komitmen dari siswa untuk peduli lingkungan, mulai dari lingkungan sendiri.

\section{KESIMPULAN}

Gerakan zero waste berhasil dilaksanakan pada siswa SMPN 2 Sekotong, Kabupaten Lombok Barat. Kegiatan ini memberikan pemahaman bagi siswa-siswa tentang peduli lingkungan dan aksi nyata yang dapat dilakukan dalam menjaga lingkungan melalui gerakan 3R. Selain itu, siswa mendapatkan pemahaman mengenai pemanfaatan kembali sampah menjadi barang yang lebih berguna.

\section{UCAPAN TERIMA KASIH}

Ucapan terimakasih kepada Universitas Mataram yang telah memfasilitasi kegiatan pengabdian pada masyarakat. Selain itu ucapan terimakasih juga kami tujuan kepada Kepala Sekolah SMP Negeri 2 Sekotong atas kesediaannya sebagai mitra dan memberikan fasilitas berupa ruangan dan perlengkapan lainnya.

\section{REFERENSI}

Dapo.dikdasmen.kemendikbud. 2019. Profil dan data pokok SMP Negeri 2 Sekotong.

Davidson, G. 2011. Waste management practices: Literature review. Diakses pada 18 Februari 2019.

Kompas.com. Indonesia darurat sampah. 27 Januari 2016

Kompas.com. Sampah plastik dunia dalam angka. 21 November 2018.

Moerdjoko S, Widyatmoko. 2012. Menghindari,mengolah dan menyingkirkan sampah,Cet.1. PT. Dinastindo Adiperkasalnternasional.

Peraturan Daerah Kabupaten Lombok Barat Nomor 3 Tahun 2017 tentang Pengelolaan Sampah. 
Peraturan Daerah Kota Mataram Nomor 10 tahun 2018 tentang Pengelolaan Sampah.

Ritchie H, Roser M. 2018. Plastik Pollution. www.ourworldindata.org.

Snow W, Dickinson J. 2001. The end of waste: zero waste by 2020. Diakses pada 18 Februari 2019.

Zambana, FL, et al. 2019. Strategi Adaptasi Masyarakat Terhadap Sampah Limbah Rumah Tangga Dengan Mengaplikasikan 3R (Recycle, Reuse, Dan Reduce) Di Desa Jerowaru. Jurnal Warta Desa 1(1),99-105. 